\title{
CONSIDERATIONS ABOUT CONTROLLED CAPACITORS
}

\author{
Adrian Plesca *
}

\begin{abstract}
A new type of thermal controlled capacitor has been developed and studied. The capacitor non-linearity depends on the control parameter - temperature. At constant temperatures, the charge versus voltage curve is non-linear and has thermal inertia. Actually, it is a new method to modify the capacitors' capacitance using the thermal field as a command parameter and brings new technical solutions for protection of electrical equipment.
\end{abstract}

K e y w or d s: thermal controlled capacitor, thermal field, dielectric

\section{INTRODUCTION}

It is not obviously an easy task to design and develop new type of capacitors taking into account the huge variety of nowadays capacitors for different applications. One can mention the trench capacitor developed for RF applications, [1] which is integrated in the front end of the line of passive integration technology. This so-called SilCap (silicon capacitor) device features very high capacitance density, extreme low-voltage dependence, excellent temperature stability, good RF performance and a high breakthrough voltage. It has been developed small capacitor bank, [2] for plasma physics and pulsed power technologies which need huge amount of energy during very short times. The main features of this system are $1.2 \mu \mathrm{F}$ of capacitance, $30 \mathrm{kV}$ maximum charge voltage, $33 \mathrm{nH}$ inductance, $500 \mathrm{~J}$ of energy, $180 \mathrm{kA}$ at the peak of current and $\mathrm{d} I / \mathrm{d} t \approx 10^{11} \mathrm{~A} \mathrm{~s}^{-1}$. In [3], is shown that dielectric properties can be modified through a combined external uniaxial stress and dc bias field. Metal-oxidesemiconductor capacitor arrays are fabricated on both $\mathrm{P}$ and $\mathrm{N}$ type silicon wafers using layer-by-layer (LbL) selfassembled insulating layers, [4]. The vertical dimension of the self-assembled thin film can be precisely controlled as well as the molecular order. Unlike the conventional process, the LbL self-assembly allows one to obtain the thin films for a semiconductor device with a dramatically lower temperature, lower cost and shorter processing time. The deposited thin film is stable and can grow on any substrate other than silicon. The conventional lithographic technique is employed to pattern the self-assembled thin films, resulting in an extremely high reproducibility. This enables the possibility of industrial applications to fabricate devices with this simplified and versatile technique. In [5] a study is presented on the design and fabrication of a three-paired-electrodes voltage controlled capacitor with a complex membrane on a high-resistivity silicon substrate. The complex membrane is composed of a 0.8 micron $\mathrm{Al}$ and 0.15 micron SiON realized using sputtering. The suspended membrane structure is obtained with polyimide as the sacrificial layer. There are also current and voltage controlled capacitors special designed for charging schemes [6], inverters [7,8], and single-phase induction motor [9].

In this paper a new type of controlled capacitor has been studied and developed. Its electric characteristics have been analyzed and the conclusions outline the possibilities to use it as a protection component part at low voltage electrical apparatus.

\section{THERMAL CONTROLLED CAPACITOR}

From the previous theoretical and experimental work, [10-15], related to ferroelectric dielectrics which allow the dielectric permittivity variation against temperature, a capacitor based on $\mathrm{BaSrTiO}_{3}$ dielectric, has been achieved like a good solution. This is a thermal controlled capacitor and can be used at static switching processes from different automatic control and protection systems. Usually, in the field of electrical equipments, the static switching process is achieved through the following solutions:

- controlled resistors type transistor, thyristor, triacs, etc;

- controlled inductance type commanded coils;

- electric controlled capacitors (it uses an auxiliary electric field from a voltage supply source).

The capacitor non-linearity is because of non-linear behaviour of ferroelectric dielectrics when a command signal is provided. The main known substances with ferroelectric properties are the Seignette salt $\left(\mathrm{KNaC}_{4} \mathrm{H}_{4} \mathrm{O}_{6}+\right.$ $\left.4 \mathrm{H}_{2} \mathrm{O}\right)$ and ferroelectric titanites such as $\mathrm{BaTiO}_{3}$. The most important properties related to ferroelectrics are the following:

- high dielectric permittivity, that allow to build capacitors with high values at small dimensions;

* Gh. Asachi Technical University of Iasi, Blvd. D.Mangeron, 51-53, Iasi 700050, Romania; aplesca@ee.tuiasi.ro 




Fig. 1. Constructive principle of thermal controlled capacitor

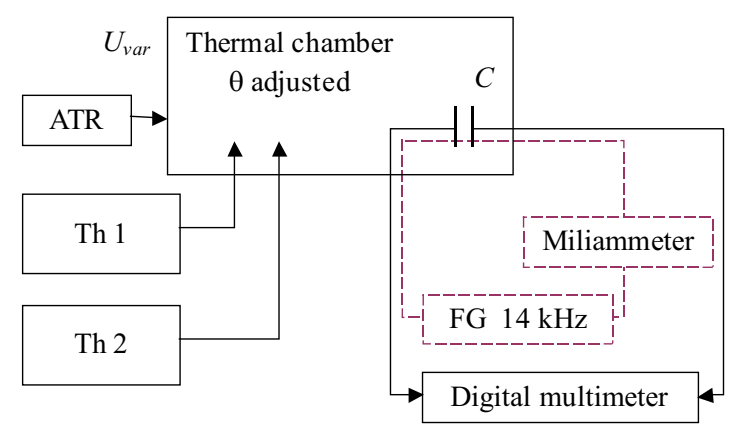

Fig. 2. The block scheme of measurement and control circuits for capacitor

- the dielectric permittivity dependence against temperature.

The thermal controlled capacity, Fig. 1, is made by a capacitor with two gold armatures $\left(\mathrm{A}_{1}\right.$ and $\left.\mathrm{A}_{2}\right)$, connected at two terminals (1-2). Between armatures there is a ferroelectric dielectric type $\mathrm{BaSrTiO}_{3}$, which is placed within a command thermal field $(\Theta)$. This allows to change the relative dielectric permittivity, hence the capacity will be modified within a temperature range from 0 to $130{ }^{\circ} \mathrm{C}$.

The capacitor has been made like a bearing disc shape with a diameter by $7 \mathrm{~mm}$ and thickness of $2.2 \mathrm{~mm}$.

This capacitor has been made following the next technological steps:

- powder preparing using chemical methods (chemical reaction in solid state starting with the oxides type $\mathrm{BaO}$ or $\mathrm{TiO}_{3}, \mathrm{SrO}_{2}$ );

- splintering;

- calcination including checking with $\mathrm{X}$ rays;

- splintering of the calcinated material;

- unidirectional and hydrostatical pressing;

- sintering together with an intensed process of contraction;

- cutting of the ceramic slices and their grinding;

- setting of the gold electrodes.

It can be built different types of capacitors with dielectric type $\mathrm{BaSrTiO}_{3}$ or other type of ferroelectric titanites, and may have high capacity with a large variation depending on input signal, even up to ten times. They have the capacity transition point depending on temperature up to $100 \ldots 110^{\circ} \mathrm{C}$. The above dielectric has structural, chemical and thermal stability.

The principle scheme used during experimental tests is shown in Fig. 2.

The temperature variation inside the thermal chamber, is made using an autotransformer ATR that allows to establish the desired test temperature. In order to obtain without doubts a steady-state uniform thermal field with temperature value $\Theta$ inside the thermal chamber, two thermocouples Th1, Th2, have been used. A thermocouple has been mounted closed to capacitor and the other at a distance about $5 \mathrm{~cm}$. The thermocouples belong to digital multimeters type DT9208A with an error of maximum $0.75 \%$ for a temperature range from $-40 \ldots 400{ }^{\circ} \mathrm{C}$. The capacity value at a certain temperature during steadystate conditions, has been measured using a digital multimeter type MASTECH MY-69, 1. There is the possibility to supply the capacitor with variable voltage between $30 \ldots 96 \mathrm{~V}$ with frequency about $14 \mathrm{kHz}$, from a frequency generator, in order to obtain the characteristic current against voltage across this capacitor. The current has been measured with the miliammeter.

The thermal effect upon the wires impedance inside the thermal chamber can be neglected because the total impedance of the current path (electric wires and contacts) is very small than capacitor impedance which is around $200 \mathrm{M} \Omega$.

The experimental characteristic of capacity against temperature, in steady-state conditions, is shown in Fig. 3. There are 130 measurement points and the temperature value inside thermal chamber has been controlled through two thermocouples.

From this characteristic, one observes the transition point of capacity vs temperature around $88^{\circ} \mathrm{C}$, where the capacity becomes 2.2 times bigger than initial one, within the temperature range $0 \ldots 35^{\circ} \mathrm{C}$, where the capacity is approximately constant. The temperature increasing above transition point implies the decreasing of the capacity.

The ascendent part of the characteristic capacity vs temperature, Fig. 4, which corresponds to the temperature range of $0 \ldots 88^{\circ} \mathrm{C}$, can be used at different protection electrical apparatus applications.

The capacity against temperature variation law in the case of ferroelectric dielectrics, is

$$
C=\varepsilon(\theta)\left(\theta-\theta_{0}\right)
$$

The variation curve $C(\theta)$ can be approximated with a polynomial function using the method of global interpolation. This method allows to establish an approximate function for the whole variation range. The analysis of the ascendant portion of the characteristic capacity against 




Fig. 3. The capacity vs temperature curve

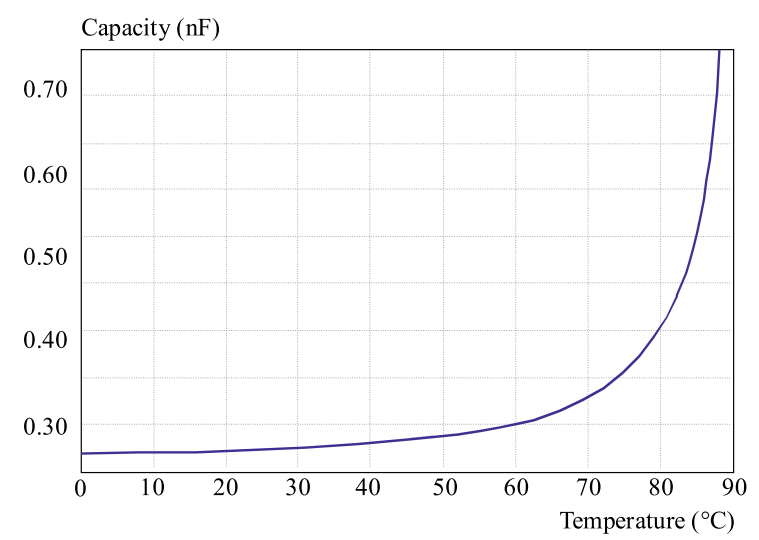

Fig. 5. The approximation characteristic capacity vs temperature

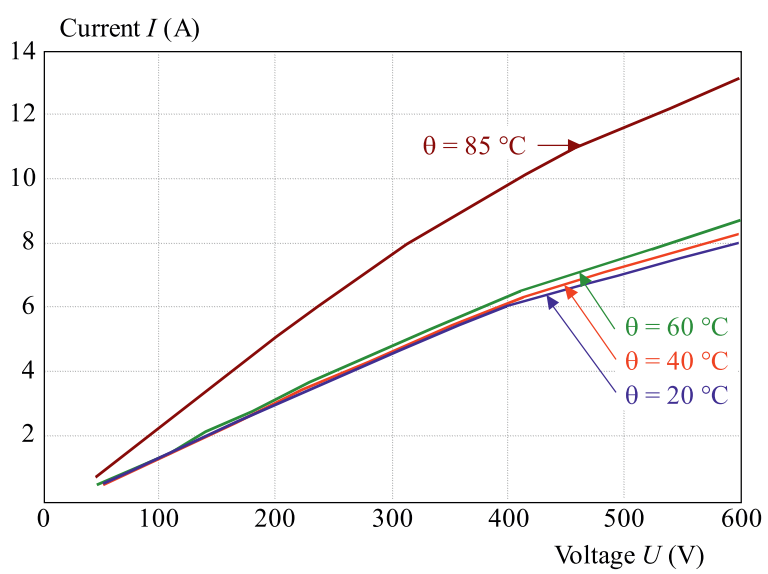

Fig. 7. The experimental characteristics current vs. voltage at $14 \mathrm{kHz}$

Table 1. Time values for the maximum capacity

\begin{tabular}{|c|c|}
\hline Step temperature $\Theta\left({ }^{\circ} \mathrm{C}\right)$ & Time $\mathrm{t}(\mathrm{min})$ \\
\hline 88 & 11 \\
\hline 105 & 6 \\
\hline 120 & 3.4 \\
\hline
\end{tabular}

temperature has been made using the Table-Curve software. The result is shown in Fig. 5.

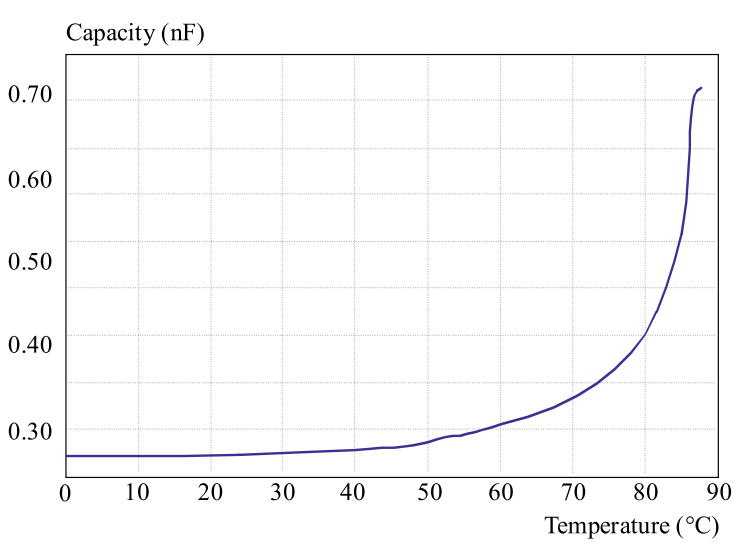

Fig. 4. The ascendant part of the characteristic capacity vs temperature



Fig. 6. The experimental characteristics of capacitor thermal inertia for a step temperature of 88,105 and $120^{\circ} \mathrm{C}$

The equation is

$$
C=\frac{a+c \theta}{1+b \theta+\mathrm{d} \theta^{2}}
$$

where the coefficients have the following values:

$$
a=0.319 ; b=-0.01 ; c=-0.003 ; d=-7.473 \times 10^{6} \text {. }
$$

A family of three experimental characteristics of thermal inertia of the capacitor in the case of three step temperature values of 88,105 and $120^{\circ} \mathrm{C}$, are shown in Fig. 6 .

The time values when the capacity has the maximum value are presented in Tab. 1. It notices from the diagrams that when the capacitor is introduced inside thermal field with the temperature of $88^{\circ} \mathrm{C}$, which corresponds to Curie point, the capacity increases up to maximum value and maintains this value in time. In the case of the other temperature values of 105 and $120^{\circ} \mathrm{C}$, the capacity reaches the maximum value, when the dielectric temperature has $88^{\circ} \mathrm{C}$, then the capacity decreases when the dielectric temperature increases above Curie point.

The non-linearity feature of the capacitor is defined by the characteristic charge against voltage $q(u)$ which is similarly to the characteristic current against voltage $i(u)$. The experimental tests have been made for the following constant temperature values: $20,40,60$ and $85^{\circ} \mathrm{C}$. 
The voltage supply at the frequency of $14 \mathrm{kHz}$, for the capacitor, has been provided by a frequency generator FG, as shown in Fig. 2. The experimental characteristics are shown in Fig. 7.

As it can be noticed from the above characteristics, during every test temperature value, the current flowing through the capacitor increases when the voltage supply increases too. There is a non-linear variation current against voltage supply.

\section{CONCLUSIONS}

The theoretical aspects related to the thermal controlled capacitor and all the experimental tests outline the following conclusions:

- the capacitor non-linearity depends on an external (command) parameter; the temperature; hence, the capacitor is a self-parametric type;

- at constant temperatures, the characteristic charge vs voltage is a non-linear one, because the characteristic current vs voltage is non-linear too; that means the capacitor is a non-linear one;

- the capacitor has thermal inertia, hence this type of capacitor is an inertial one.

The technical solution has the following advantages:

- it is a new method to modify the capacitors' capacity using like command parameter the thermal field;

- it is a new technical solution for protection electrical equipments;

- allow to build resonance and ferroresonance circuits with linear/non-linear coil and non-linear capacitor;

- the capacitor control is made using thermal field, a phenomena with industrial applications;

- allow to build thermal relays if the controlled capacitor is used like thermal capacity sensor;

- it has a reproducible behaviour related to the same characteristic $C(\Theta)$, and the capacity return to the same initial value after repeated applied thermal fields.

\section{REFERENCES}

[1] GEISELBRECHTINGER, A.-BÜYÜKTAS, K.-ALLERS, K.-HARTUNG, W.: A High-Performance Trench Capacitor Integrated in a Passive Integration Technology, Semicond. Sci. Technol. 24 (2009).

[2] TARifeno, A.-PAVEZ, C.-SOTO, L. : Design and Characterization of a Small Multipurpose Capacitor Bank for Plasma Physics and Pulsed Power Experiments, Phys. Scr. T131 (2008).
[3] YANG, G.-YUE, Z.-SUN, T.-GOU, H.-LI, L. : Effect of Combined External Uniaxial Stress and dc Bias on the Dielectric Property of $\mathrm{BaTiO}_{3}$-Based Dielectrics in Multilayer Ceramic Capacitor: Thermodynamics and Experiments, J. Phys. D: Appl. Phys. 41 (2008).

[4] HUA, F.-SHI, J.-LVOV, Y.-CUI, T.: Fabrication and Characterization of MetalOxideSemiconductor Capacitor Based on Layer-by-Layer Self-Assembled Thin Films, Nanotechnology 14 (2003), 453-457.

[5] WEI, J.-LIU, Z.-FANG, J.-LIANG, X.-LIU, L.-LI, Z. : The Study on a Voltage Controlled Capacitor with Complex Membrane, Proceedings 7th International Conference on Solid-State and Integrated Circuits Technology, vol. 3, 2004, pp. $1707-1710$.

[6] ELWELL, R.-CHERRY, J.-FAGAN, S.-FISH, S.: Current and Voltage Controlled Capacitor Charging Schemes, IEEE Transactions on Magnetics 31 (1995), 38-42.

[7] CHAKRABORTY, C.-DALAPATI, S.-BHATTACHARYA, S. : Performance Evaluation of Controlled-Capacitor-ChargingType Inverters, IEEE Transactions on Industrial Electronics $\mathbf{5 6}$ (2009), 12-19.

[8] DALAPATI, S.-CHAKRABORTY, C.-BHATTACHARYA, S. : Single Phase, Full Bridge, Controlled Capacitor Charging (CCC) Type Inverter, IEEE International Conference on Industrial Technology, 2006, pp. 265-270.

[9] LeTtenMaieR, T. A.-NOVOTNY, D. W.-LIPO, T. A.: Single-Phase Induction Motor with an Electronically Controlled Capacitor, IEEE Transactions on Industry Applications 27 (1991), 38-43.

10] AVELIN, J.-SIHVOLA, A.: Polarizability of Polyhedral Dielectric Scatterers, Microwave and Optical Technology Letters 32 (2001), 60-64

[11] GIORDANO, S. : Multipole Analysis of a Generic System of Dielectric Cylinders and Application to Fibrous Materials, Journal of Electrostatics 63 (2005), 1-19.

[12] MIELKE, A.-TIMOFTE, A. M.: An Energetic Material Model for Time-Dependent Ferroelectric Behavior: Existence and Uniqueness, WIAS Publications Berlin (2005).

13] SCHIEBER, D.: Journal of Electrostatics 48 (1999 Dielectric Rod in the Field of Two Parallel Plates), 65-75.

[14] SIHVOLA, A.-VENERMO, J.-YLA-OIJALA, P.: Dielectric Response of Matter with Cubic, Circular-Cylindrical, and Spherical Microstructure, Microwave and Optical Technology Letters 41 (2004), 245-248.

[15] VENERMO, J.-SIHVOLA, A.: Dielectric Polarizability of Circular Cylinder, Journal of Electrostatics 63 (2005), 101-117.

Received 13 March 2009

Adrian Plesca was born in Iasi, Romania, on April 16, 1972. He graduated from the Gh. Asachi Technical University of Iasi and received the PhD degree in Electrical Engineering in 2001. His employment experience included the Gh. Asachi Technical University of Iasi, Power Engineering Department. His special fields of interest included electrical apparatus, special equipment for power semiconductor devices protection and 3D modelling and simulation of the electrical apparatus. Plesca received Golden and Silver Medals at the World Exhibition of Invention, Research and Industrial Innovation, Brussels, Belgium, EUREKA, 2001, 2004. 